\title{
Response of Arakawa-Schubert Cumulus Parameterization Model to Real Data in the Heavy Rainfalls Area
}

\author{
By K. Yamazaki \\ Meteorological Research Institute, Tsukuba 305, Japan \\ and K. Ninomiya \\ Electric Computation Center, Japan Meteorological Agency, Tokyo 100, Japan \\ (Manuscript received 8 April 1980, in revised form 1 June 1981)
}

\begin{abstract}
Real data response of Arakawa-Scubert cumulus parameterization (CU) is studied for the case of heavy rainfalls occurred over Kyushu (western part of Japan) on June 27, 1972.

We study the influence of large-scale forcing on heavy rainfalls through time-integration of a simple one-dimensional model including CU, large-scale condensation (LSC) and middlelevel convective adjustment (ML) with observed rate of large-scale heating and moistening. Model simulates observed features well. Results indicate that ML plays an important role in warm sector of depression, while LSC and CU play around the trailing portion of front where heavy rainfalls occur. During the earlier period of heavy rainfalls, LSC plays an important role and during the latter half period $\mathrm{CU}$ plays an important role. $\mathrm{CU}$ and $\mathrm{ML}$ work to stabilize the stratification cancelling the stability change caused by large-scale forcing.
\end{abstract}

\section{Introduction}

Various cumulus parameterization models have been developed for atmospheric general circulation model (GCM) and numerical prediction model. Among them, Arakawa-Schubert model (Arakawa and Schubert (1974)) seems to be the most sophisticated one for GCM at present. A-S model has been also applied to various numerical prediction models and simulation models. For example, McGregor et al. (1978) examined the performance of a fine-mesh limitedarea prediction model which includes A-S model. Wada (1977) investigated the properties of typhoon-scale disturbances produced with A-S parameterization by a linear analysis.

In recent years, many diagnostic studies on the interaction between large-scale circulation systems and convection have been performed in the basis of spectram representation of the cumulus ensemble proposed by Arakawa and Schubert (1974) (e.g., Yanai et al. (1973), Ogura and Cho (1973), Nitta (1975, 77, 78), Johnson (1976, 78), Cho and Ogura (1974), Yanai et al. (1976), Lewis (1975)). It should be noted that almost all of the aforementioned studies were made in tropical marine region except the work by Lewis.

During the presummer rain season, large amount of rain falls within a subtropical frontal zone (Baiu front) extending from southeastern China to Japan Islands. The heavy rainfalls are usually associated with large- or medium-scale frontal depression.

Detailed observational studies (e.g., Matsumoto and Akiyama (1970), Ninomiya and Akiyama (1972), Akiyama (1973, 74, 78)) revealed characteristic features of cumulus activity in Baiu frontal disturbances. Although Ninomiya and Yamazaki (1979) and Akiyama (1979) estimated cloud height, mass flux and change of stratification due to release of instability by applying an adjustment-type A-S model, which was developed by Yamazaki for GCM of Meteorological Research Institute, to stratification observed in heavy rainfalls, the interaction between cumulus and the disturbance was not fully elucidated yet.

In the present paper we intend to study interaction among cumulus clouds and large-scale environment by applying the A-S model to the stratification and rates of large-scale heating and 
moistening observed in the heavy rainfalls occurred in June 27, 1972 over Kyushu (western part of Japan). The purpose of the present paper is to examine the response of the A-S model to the situation in the sub-tropical convective region. We expect to get further understanding of the convective process and cumulus interaction of the subtropical heavy rainfall through this experiment.

\section{Synoptic situation of the heavy rainfalls of June 27, 1972}

A Baiu frontal depression brought heavy rainfalls over Kyushu (western part of Japan) on June 27, 1972. Synoptic-scale feature of the frontal depression were described in detail by Ninomiya (1978). Meso-scale analysis on precipitation and radar echoes, preliminary survey of convections and the heat energy budget analysis were also performed by Ninomiya and Yamazaki (1979) (hereafter we call this paper NY).

Since the detailed description about the heavy rainfalls of the present case already given in those paper, we give very brief description here. The depression has passed the north of Kyushu northeastward accompanying warm and cold fronts. The area of weak and continuous precipitation ( $\sim 5 \mathrm{~mm} / 3$ hour) extended $\sim 1,000 \mathrm{~km}$ ahead of the depression, while extremely strong rainfalls took place around the trailing portion
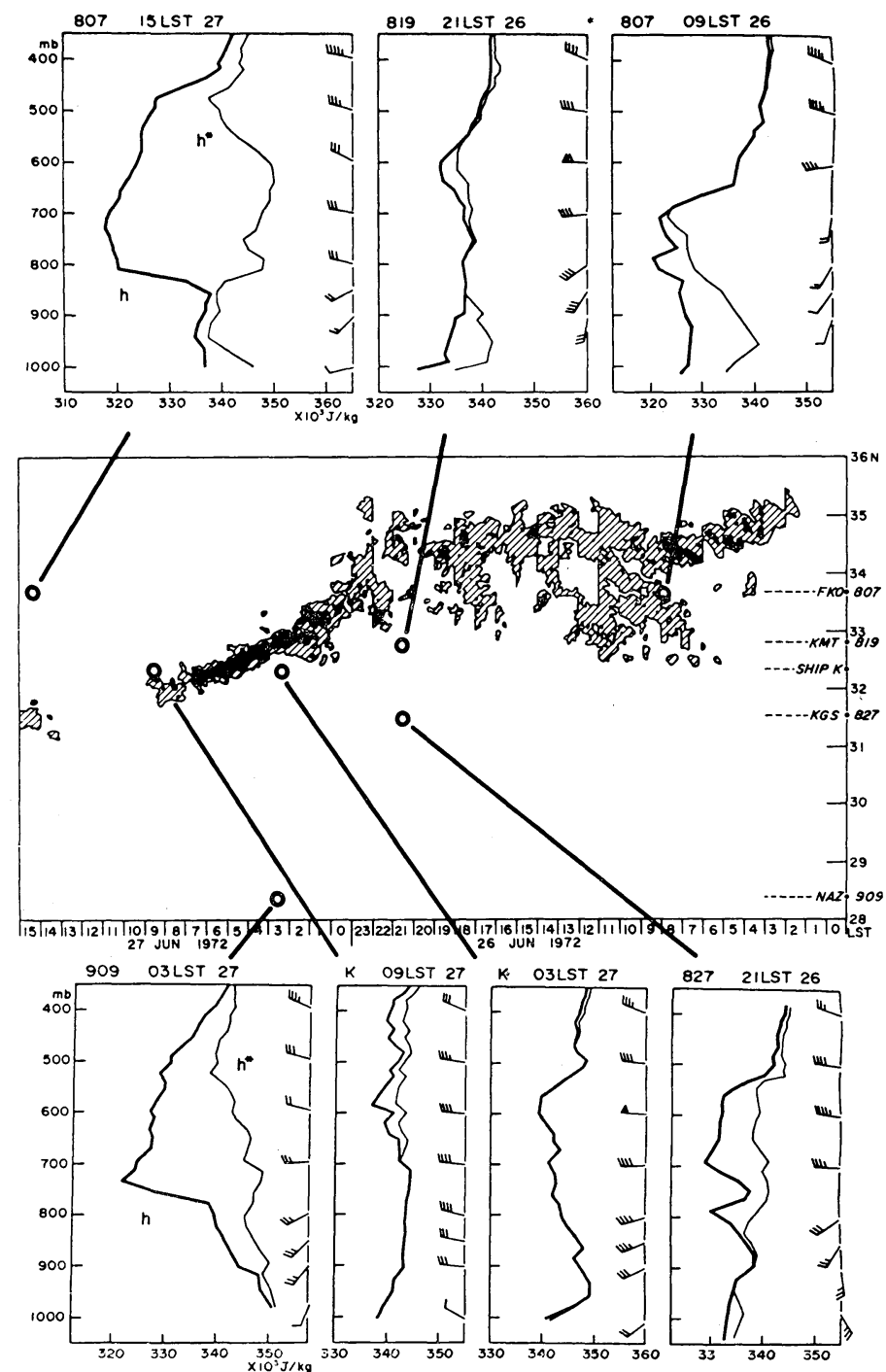

Fig. 1 Vertical profiles $h, h^{*}$ and wind at the selected points in time-lapse composite echo maps. 
of front (see the surface maps and precipitation maps for the period from 21 LST June 26 to 15 LST June 27, 1972 presented in Fig. 1 of NY). The heavy rainfalls did not propagate with the depression, but it occurred in the limited period (03 09 LST 27) when the moist tropical marine air-mass was most effectively transported toward the warm sector of the depression. The heavy rainfalls ceased after 10 LST as the depression occluded.

Time-lapse composite radar echo map of the frontal depression and vertical profiles of moist static energy $h$, saturated moist static energy $h^{*}$ and the observed wind velocity at the selected points are shown in Fig. 1.

In this paper, 6 hourly aerological data at 4 stations (shown in Fig. 2) for 3 days period from 21 LST 25 to 03 LST 28 June 1972 was analysed. We describe the location of these 4 stations relative to the heavy rainfall area; Fukuoka (807) was located to the north of the heavy rainfall area, while Kumamoto (819), research ship Keifu and Kagoshima (827) was in the northern, southwestern and southern part of the heavy rainfall area respectively.

In NY, evaluation of various thermodynamical quantities were made for A-area enclosed by these 4 stations. In this paper, we use these A-area mean values.

Vertical-time section of mixing ratio of water vapor, relative humidity, and equivalent temperature (moist static energy divided by specific heat of constant pressure i.e., $h / c_{p}$ ) over A-area are

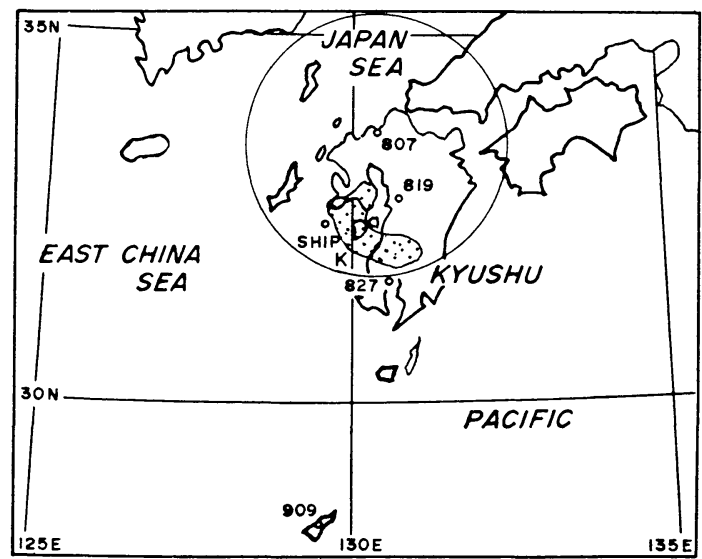

Fig. 2 Upper air observation stations used in the present study. The circles indicate $200 \mathrm{~km}$ range of Mt. Seburi meteorological radar. Dotted area indicates severe rainfall area where precipitation in 30 hours exceeded $120 \mathrm{~mm}$. shown in Fig. 3. Before heavy rainfall period, when A-area located in the warm sector of depression, air was moist but stratification was not so unstable. Around 09 LST 27, very moist air invaded in lowest layer and stratification became unstable. After the passage of cold front, very dry air invaded into A-area and stratification became very stable.

\section{Outline of the experiment}

In the present section, we will study the influence of large-scale forcing on heavy rainfalls through time-integration of a simple onedimensional model with observed rates of largescale heating and moistering evaluated over the heavy rainfall area (A-area).

\section{One dimensional model}

The present 1-dimensional model contains following processes;

(1) large-scale condensation (L.S.C.) for whole layer,

(2) middle layer convective adjustment (M.L.)

for free atmosphere, and

(3) cumulus parameterization (C.U.), i.e.,

$$
\begin{aligned}
\frac{\partial T}{\partial t} & =\left(\frac{\delta T}{\delta t}\right)_{L S C}+\left(\frac{\delta T}{\delta t}\right)_{M L}+\left(\frac{\delta T}{\delta t}\right)_{C U} \\
& +\left(\frac{\delta T}{\delta t}\right)_{L S}
\end{aligned}
$$

and

$$
\begin{aligned}
\frac{\partial q}{\partial t} & =\left(\frac{\delta q}{\delta t}\right)_{L S C}+\left(\frac{\delta q}{\delta t}\right)_{M L}+\left(\frac{\delta q}{\delta t}\right)_{C U} \\
& +\left(\frac{\delta q}{\delta t}\right)_{L S}
\end{aligned}
$$

where

$$
\left(\frac{\delta T}{\delta t}\right)_{L S}=-\frac{1}{\pi}\left(\bar{V}_{3} \cdot \nabla_{3} \bar{\theta}\right)
$$

and

$$
\left(\frac{\delta q}{\delta t}\right)_{L S}=-\bar{V}_{3} \cdot \nabla_{3 \bar{q}}
$$

are the large-scale heating and moistening terms respectively. We integrate these equations for 1 -hour. At the beginning of each 1-hour integration period, we give the initial stratification and large-scale forcing which are obtained by time-interporation of the observed (evaluated) values from the 6-hourly upper observation data. The cubic spline function is used for time-interpolation.

LSC occurres when the air is saturated and the excess water vapor changes into liquid water. 


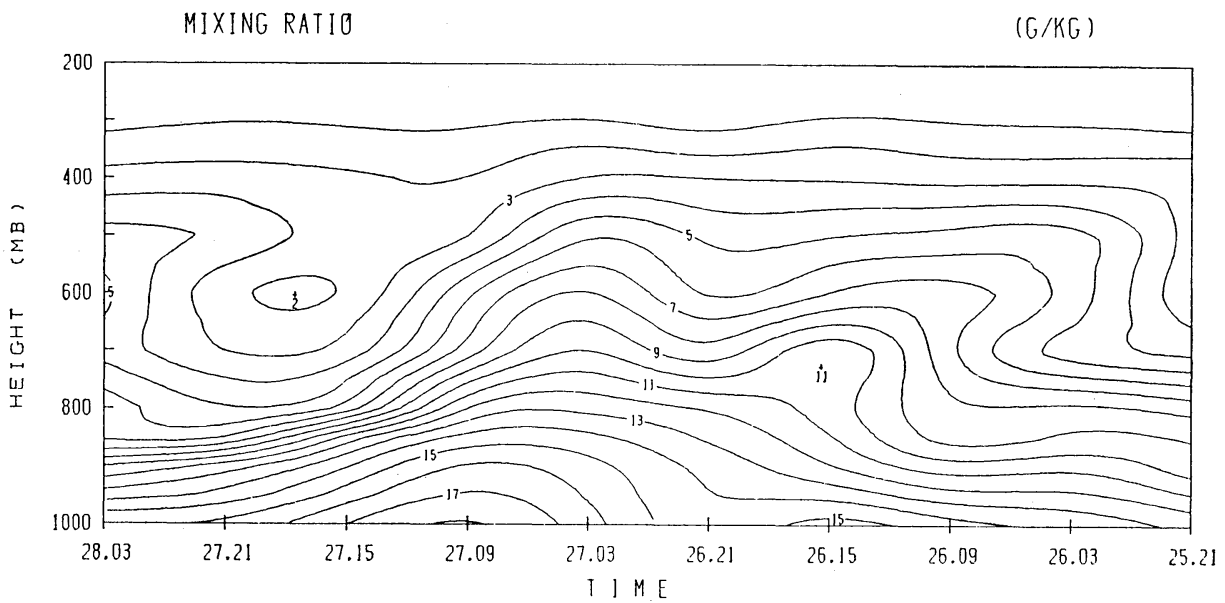

RELATIVE HUMIDITY

(\%)

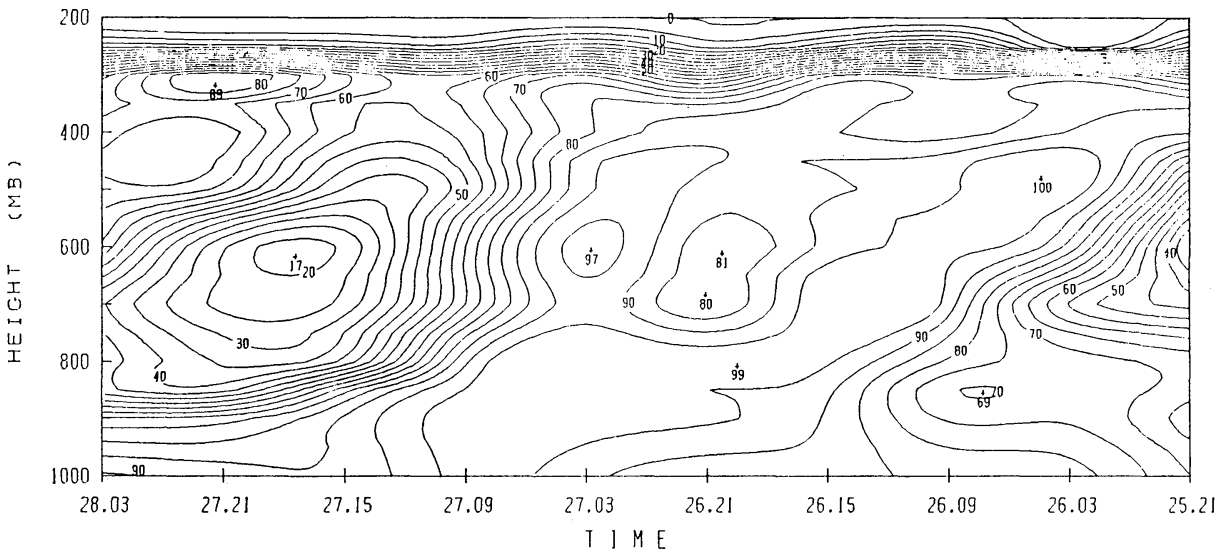

EQUIVALENT TEMPERATURE H/CP

( K)

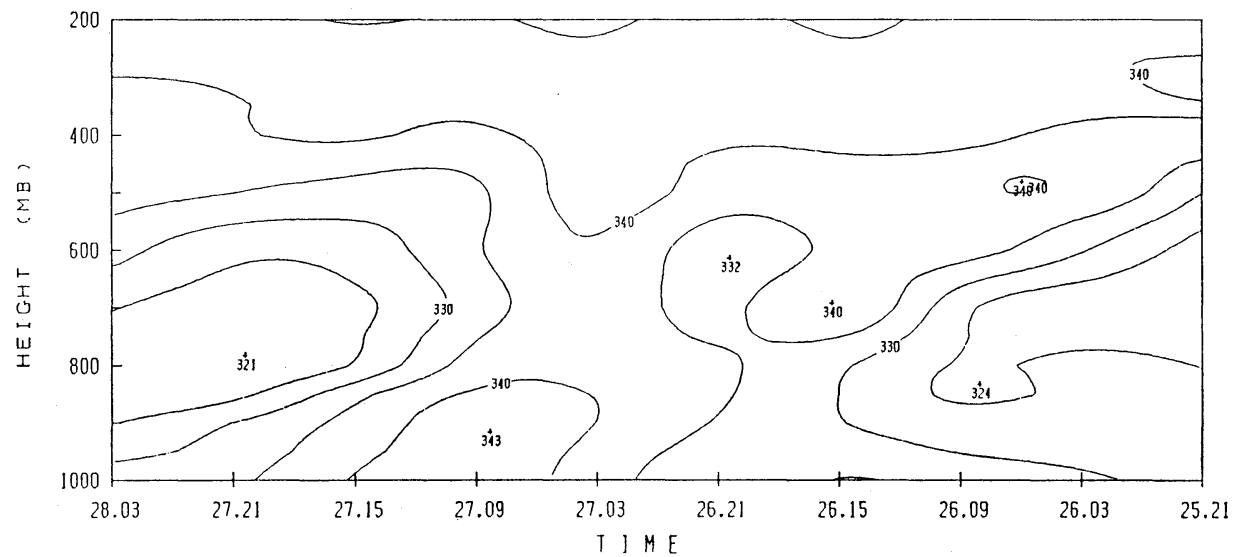

Fig. 3 Vertical time sections of observed temperature, relative humidity and equivalent temperature $h / c_{p}$ over A-area. 
The liquid water drops into the next layer and evaporates to moisten and cool the layer. The precipitation of LSC is defined as the amount of liquid water dropped from the lowest layer.

ML is applies in free atmosphere (the layer above $900 \mathrm{mb}$, in the present study). ML occurres when the moist static energy of $i$-th layer $h_{i}$ exceeds the saturated moist static energy of the immediate next upper layer ( $i-l$-th layer) $h_{i-l} l^{*}$. (See detailed description in Chapter XII of Arakawa and Mintz (1974).).

$\mathrm{CU}$ formulates the effects of cloud of which base is in PBL. Values of "baseline cloud work function $A_{0}$ " obtained by Lord and Arakawa (1980) are used in the present experiment. $\dagger$ Ice phase is included in $\mathrm{CU}$ with a simple way. (See Appendix B)

These three processes are used in Meteorological Research Institute (MRI) General Circulation Model (GCM). (See detailed description in Tokioka et al. (1980))

In the present model, PBL top is fixed at $900 \mathrm{mb}$, and values of $h$ and $q$ at the cloud base are given by averaged values over $900 \mathrm{mb} \sim$ surface. Both temperature and moisture gap at PBL top are set to zero. Top layer of model is $200 \mathrm{mb}$ and thickness of each subdivided layer is $50 \mathrm{mb}$, so there are 17 layers in the model. Schematic illustration of $\mathrm{CU}$ and vertical structure of our model are shown in Fig. 4.

In this model, the forcing effects of radiation, sensible and latent heat flux from the underlaying surface are not included. Although the effect of radiation $(-1 \sim-2 \mathrm{~K} /$ day) is one-order smaller than other terms, it works to enhance the cumulus clouds through the cooling at the cloud top. The evaporation and the sensible heat supply from the surface work to destabilize the stratification and enhance the cumulus clouds. In the Baiu frontal zone, however, the energy supply is small as the air is very warm and moist.

\section{Time integration}

The time step of integration is 30 minutes according to MRI-GCM diabatic process's time step. At each time step, three parameterization

\footnotetext{
$\dagger$ Values of "baseline cloud work function" as the function of cloud top height are read from Fig. 9 of Lord and Arakawa (1980). The physical implication of "baseline cloud work function" is the vertical integrated buoyant force necessary to develop the cumulus cloud against the dissipation. See Appendix A.
}

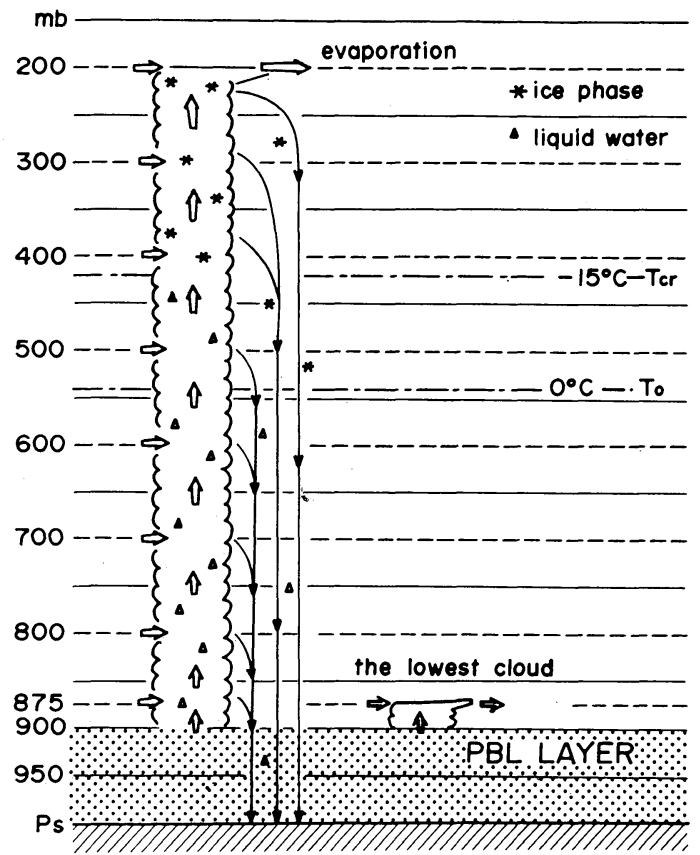

Fig. 4 Schematic illustration of cumulus model.

procecutes in the following order; LSC first, ML second and CU third.

Two time steps of integration give stratification changing rate and precipitation in 1-hour. At the beginning of each 1 hour integration, initial stratification and large-scale forcing are specified by time-interpolated observed data over A-area.

\section{Large-scale forcing}

Large-scale forcing given as external forcing are shown in Fig. 5. During heavy rainfall period, large cooling was found in the whole layer and maximum cooling reached $-7.4 \mathrm{~K} /$ hour near $400 \mathrm{mb}$. During the same period, large moistening was found in the whole layer and maximum moistening reached $4.0 \mathrm{~g} / \mathrm{kg} /$ hour near $700 \mathrm{mb}$. As a result, marked destabilization of the stratification is caused by the large-scale process.

After the passage of the cold front, large-scale warming and drying and stabilization of the stratification occurred. The intensity of these forcing was weaker than those in the heavy rainfall period.

\section{Results}

\subsection{Precipitation}

Time change of precipitation produced by the model is shown in Fig. 6A. Before 00 LST 27, precipitation intensity was weaker than $1 \mathrm{~mm} /$ hour and precipitation was mainly due to ML. 
TEMPERATURE CHANGE

0.1 C/HOUR
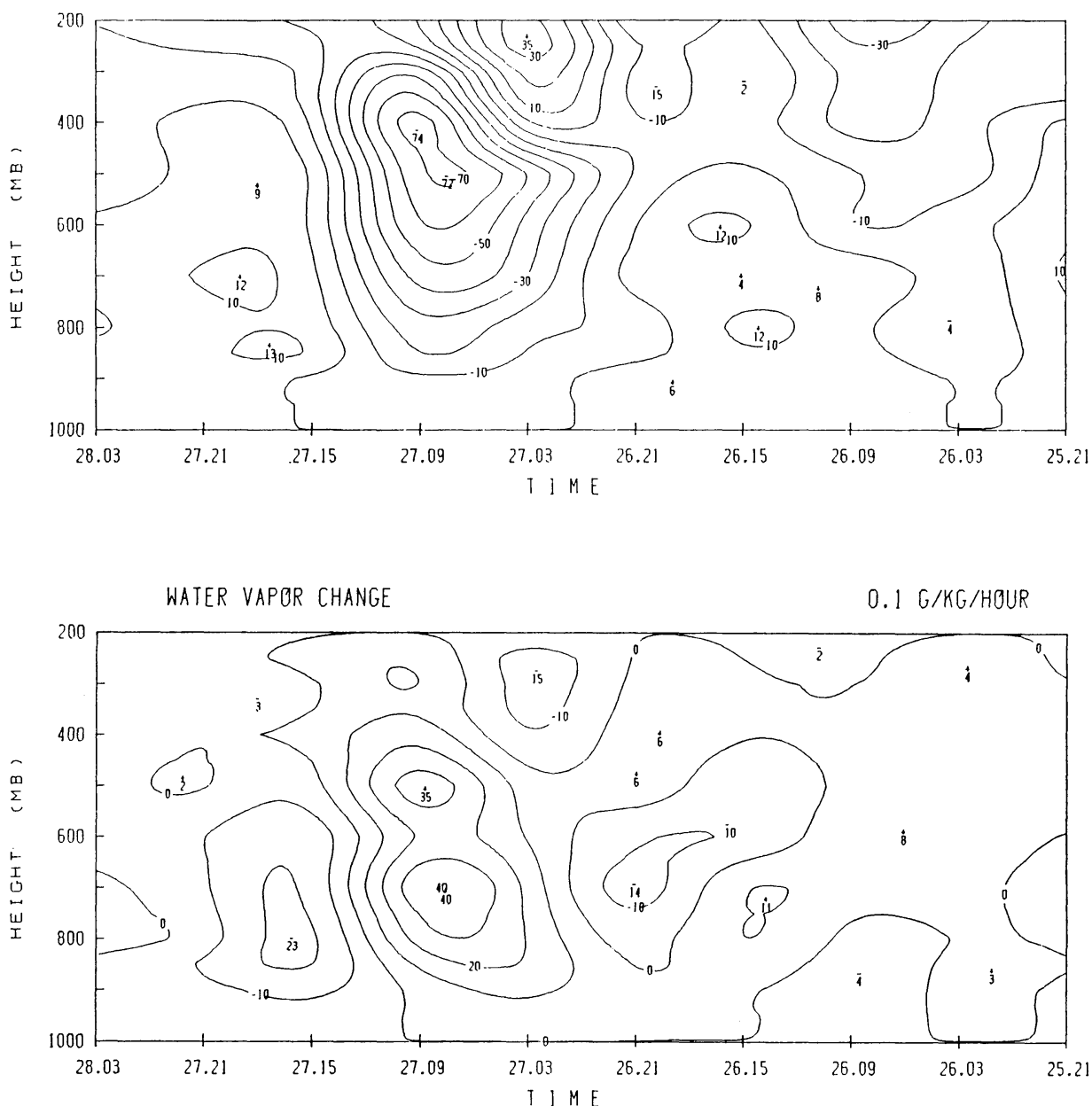

EQUIVALENT TEMPERATURE CHANG

0.1 C HOUR

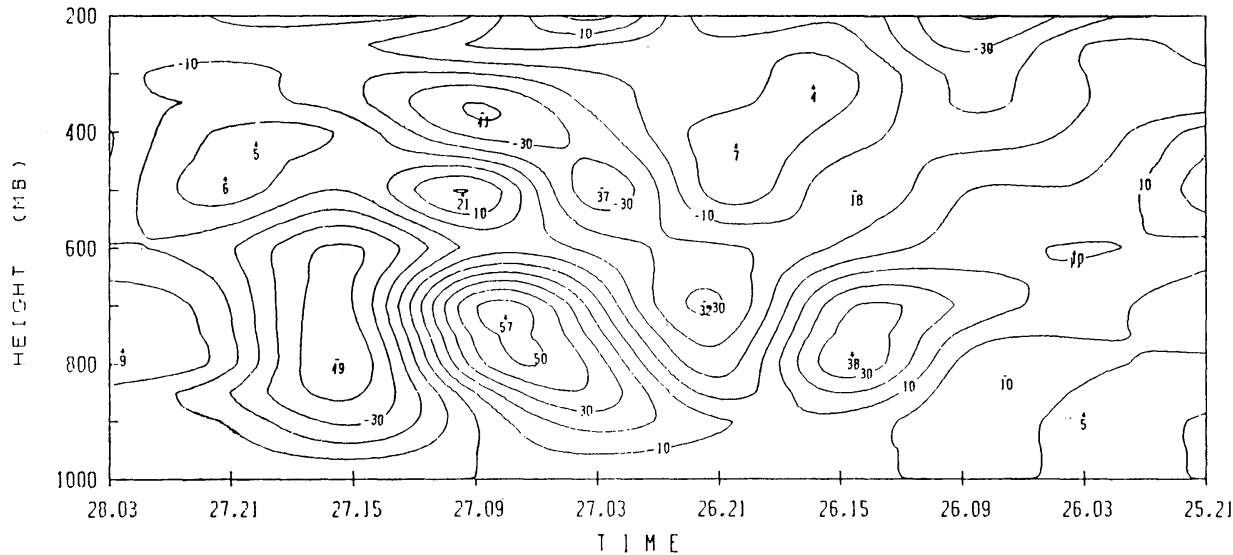

Fig. 5 Vertical time sections of large-scale forcing of temperature, moisture and equivalent temperature $h / c_{p}$ over A-area. 


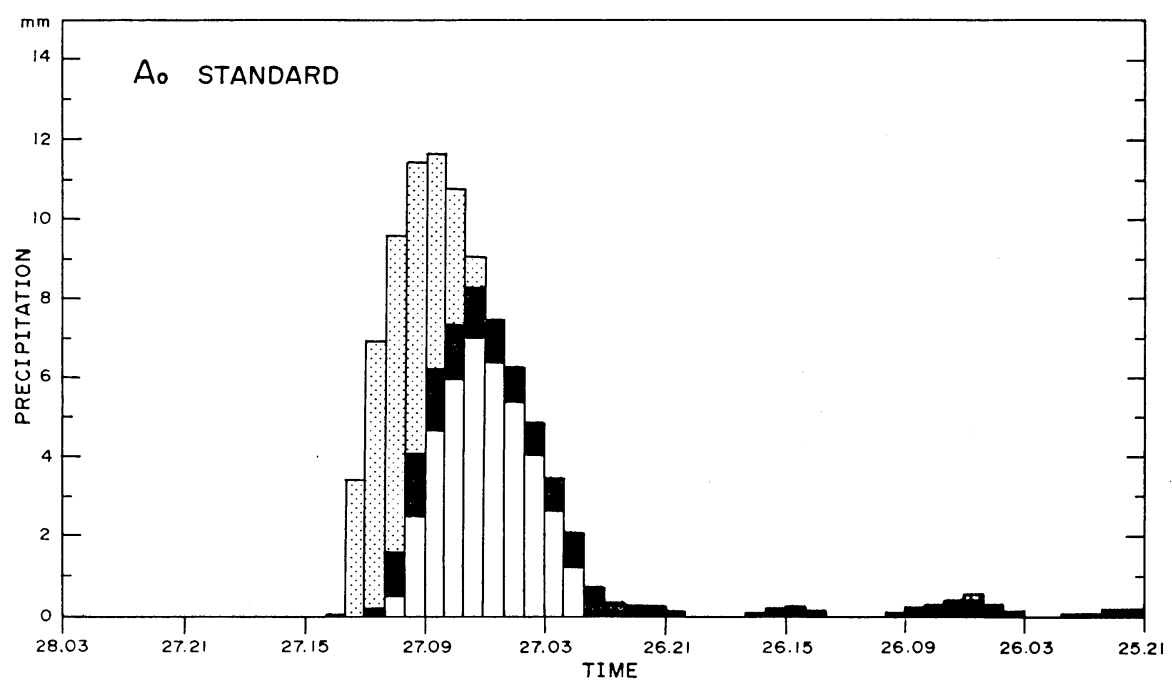

Fig. 6A Precipitation computed by the 1-dimensional model including $L S C, M L$ and $C U$. In $C U$ model, we used $A_{0}$ value of Lord and Arakawa (1980). White, black and stippled part indicate the precipitation caused by $L S C, M L$ and $C U$ respectively.

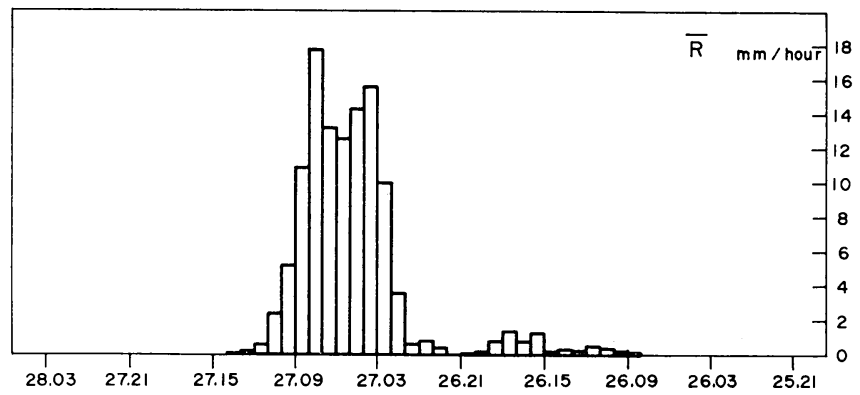

Fig. 6B The time sequence of the observed precipitation averaged over A-area.

LSC rain became stronger after 00 LST 27 and reached maximum at 06 07 LST $27 \quad(7.0$ $\mathrm{mm} /$ hour). At that time, $\mathrm{CU}$ rain appeared and became stronger and reached maximum at $10 \sim 11$ LST $27(8.0 \mathrm{~mm} /$ hour $)$. After the peak period, $\mathrm{CU}$ rain rapidly decreased. The time sequence of the observed precipitation averaged over Aarea (NY) is presented in Fig. 6B for comparison.

Maximum total precipitation rate was $11.7 \mathrm{~mm} /$ hour and occurred during 08 09 LST 27. Calculated total amount of rainfall from 21 LST 25 to 03 LST 28 is $92.6 \mathrm{~mm}$ which consists of $35.3 \mathrm{~mm}$ CU rain, $16.5 \mathrm{~mm} \mathrm{ML}$ rain and $40.4 \mathrm{~mm}$ LSC rain (Table 1).

Averaged precipitation intensity during 06 LST $27 \sim 12$ LST 27 (6 hour) is $9.9 \mathrm{~mm}$ /hour. Observed A-area averaged total precipitation was $115 \mathrm{~mm}$ and average precipitation intensity during 03 LST $27 \sim 09$ LST 27 (heavy rainfall period) was $\sim 14 \mathrm{~mm}$ /hour. The appearance of peak of calculated rainfall delayed 1 hour to that observed, and the duration of heavy rainfall in the model was longer than observed one.

As explained in section 3, the large-scale

Table 1 Total amount of precipitation computed by the model.

\begin{tabular}{|c|c|c|c|c|}
\hline \multicolumn{4}{c}{ TOTAL PRECIPITATION } & $\mathrm{mm}$ \\
\hline $\begin{array}{c}\text { CLOUD } \\
\text { CASE TYPE }\end{array}$ & $\mathrm{CU}$ & $\mathrm{ML}$ & LSC & SUm \\
\hline$A_{0}=$ STANDARO & 35.3 & 16.9 & 40.4 & 92.6 \\
\hline$A_{0}=0.0$ & 57.3 & 13.5 & 33.6 & 107.3 \\
\hline NO CU & & 17.7 & 51.6 & 69.2 \\
\hline OBSERVATION & & & & 115.0 \\
\hline
\end{tabular}


forcing terms are originally evaluated based on 6-hourly aerological data, and the time-interpolated values at 1 -hour interval are used for the model. The interpolation by spline function has smoothing effect. Therefore it is natural that there are some minor discrepancies between the calculated precipitation and observed precipitation. For example, the longer duration of the heavy rainfall in the model and its smaller peak value seems to be mainly due to this time-wise smoothing effect of the forcing terms. Except for the smoothed feature, characteristic of calculated precipitation agrees well to that of observed one.

\subsection{CU mass flux and ML mass flux}

Fig. 7 shows CU mass flux as the function of the cloud top height (cloud height spectrum representation). Calculated $\mathrm{CU}$ cloud top is at $300 \mathrm{mb}$ layer which corresponds to near $10 \mathrm{~km}$ during heavy rainfall period. This height is a little lower than radar echo height which was near $12 \mathrm{~km}$ at 0404 LST (Fig. 11 of NY). During heavy rainfall period, low $\mathrm{CU}$ cloud was not produced in the model.

Vertical time section of CU, ML and CU+ML mass flux are presented in Fig. 8. Relatively strong ( $>15 \mathrm{mb} /$ hour) ML flux was calculated below $600 \mathrm{mb}$ level. RHI radar picture at 2010 LST 26 shows that the height of the weak echo was near $5 \mathrm{~km}$ (Fig. 11 of NY).

Although there is some time lag ( $1 \sim 2$ hours $)$ between the convective process in the model and observed process, overall feature is fairly simulated by our model. Both $\mathrm{CU}$ and ML cloud represent clouds caused by instability of stratifi- cation, however, these features and roles in Baiu frontal depression are different each other. ML cloud releases instability during whole period mainly in the lower troposphere and ML mass flux does not so much increase even during heavy rainfall period. On the other hand, CU releases instability in the whole troposphere slightly after the peak of large-scale destabilization. During the earlier half of heavy rainfall period, CU plays no role, but during the latter half, $\mathrm{CU}$ plays major role.

Total CU + ML mass flux reaches maximum ( $\sim 70 \mathrm{mb} /$ hour) during 09 LST 27 10 LST 27. Large-scale upward $p$-velocities obtained by diagnostic method (see Fig. 4 of NY) have maximum value of $96 \mathrm{mb} /$ hour at 09 LST 27 at $500 \mathrm{mb}$ level. CU + ML mass flux value is nearly equal to large-scale upward motion (Fig. 9). This indicates that the large-scale mass flux have been carried mostly in the cumulus type clouds (CU and $\mathrm{ML}$ ).

\subsection{Changes in stratification}

The time-height cross section for changes of temperature and humidity by LSC obtained with model are shown in Fig. 10. During 21 LST 25 00 LST 27 upper layer was saturated and liquid water is produced. However, the liquid water is evapolated in lower layer, and rain did not reach the ground. During 03 LST 27 09 LST 27, large heating occurred by LSC in the middle layer. LSC does not change equivalent temperature.

The time-height cross section of changes in thermodynamic variables by $\mathrm{CU}$ are shown in Fig. 11. CU warmed and dried whole layer.

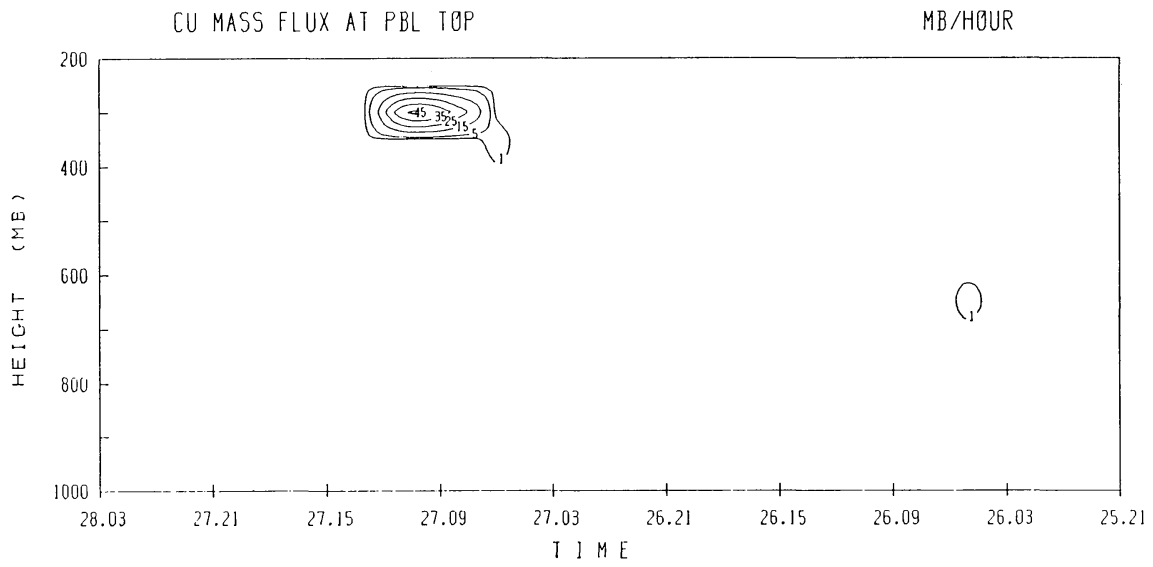

Fig. 7 Computed cumulus mass flux at $P B L$ top as the function of the cloud top height. (Cloud height spectral representation). 

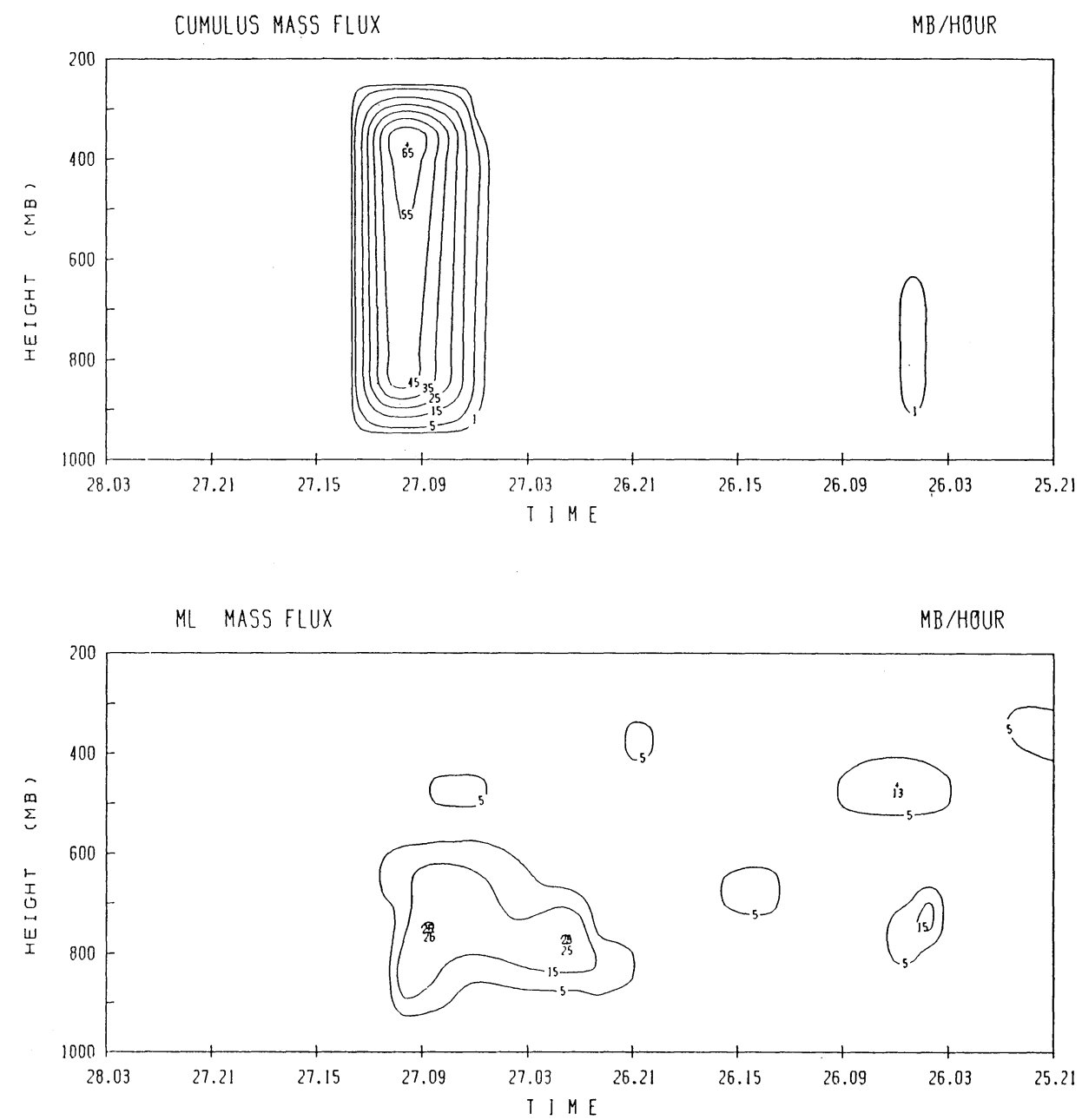

CU + ML MASS FLUX

$M B / H O U R$

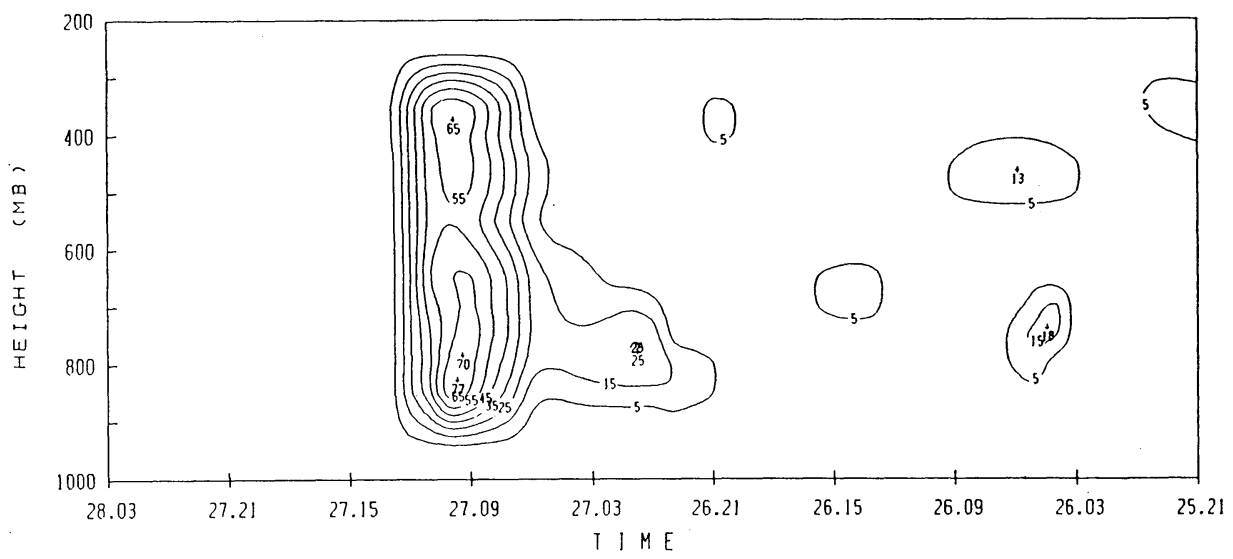

Fig. 8 Top: Vertical time section of $C U$ mass flux.

Middle: Vertical time section of $M L$ mass flux.

Bottom: Vertical time section of $C U+M L$ mass flux. 


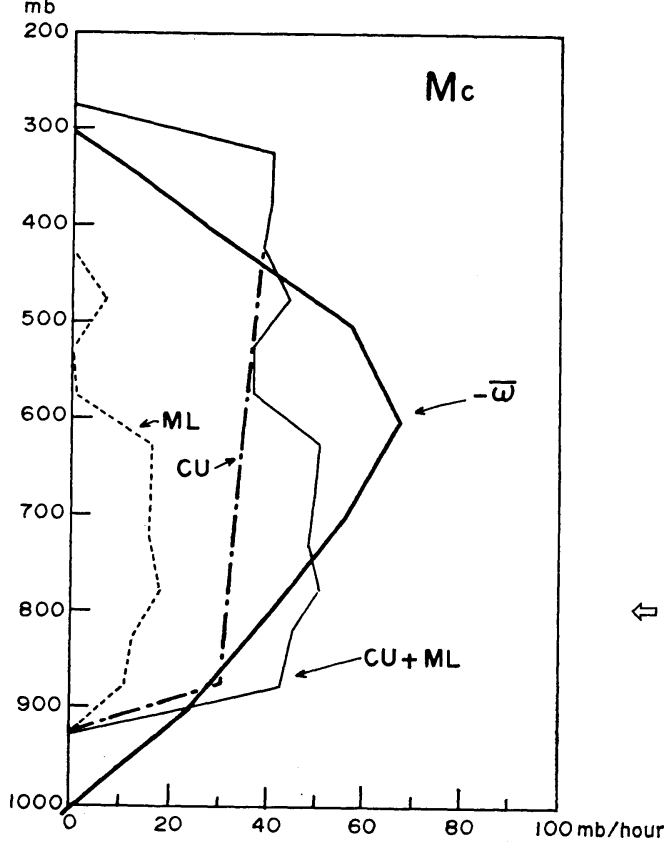

TEMPERATURE CHANGE
Fig. 9 Vertical mass flux during heavy rainfall period over A-area. A thick solid line indicates A-area mean vertical $p$-velocity during 03-09 LST 27. The dot-dash line, broken line and thin solid line indicates mean $C U$ mas sflux, mean $M L$ mass flux and mean $C U+M L$ mass flux during 06-12 LST 27, respectively.

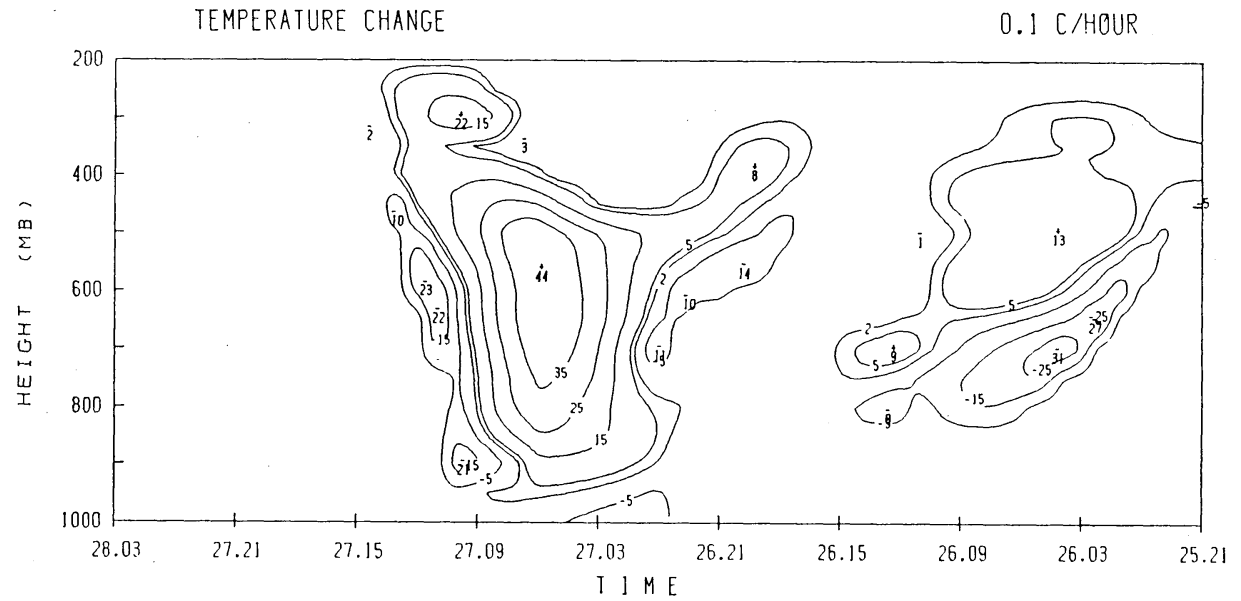

WATER VAPQR CHANGE

0.1 G/KG/HOUR

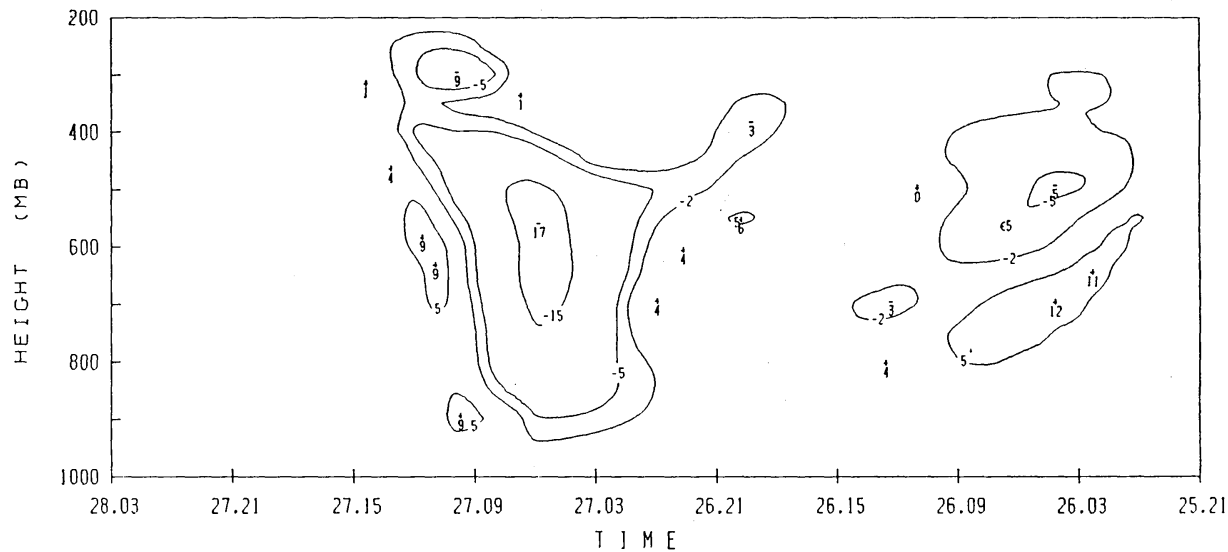

Fig. 10 Vertical time section of LSC changing rate of temperature and moisture. Unit is

$0.1 \mathrm{C} /$ hour and $0.1 \mathrm{~g} / \mathrm{kg} /$ hour. 

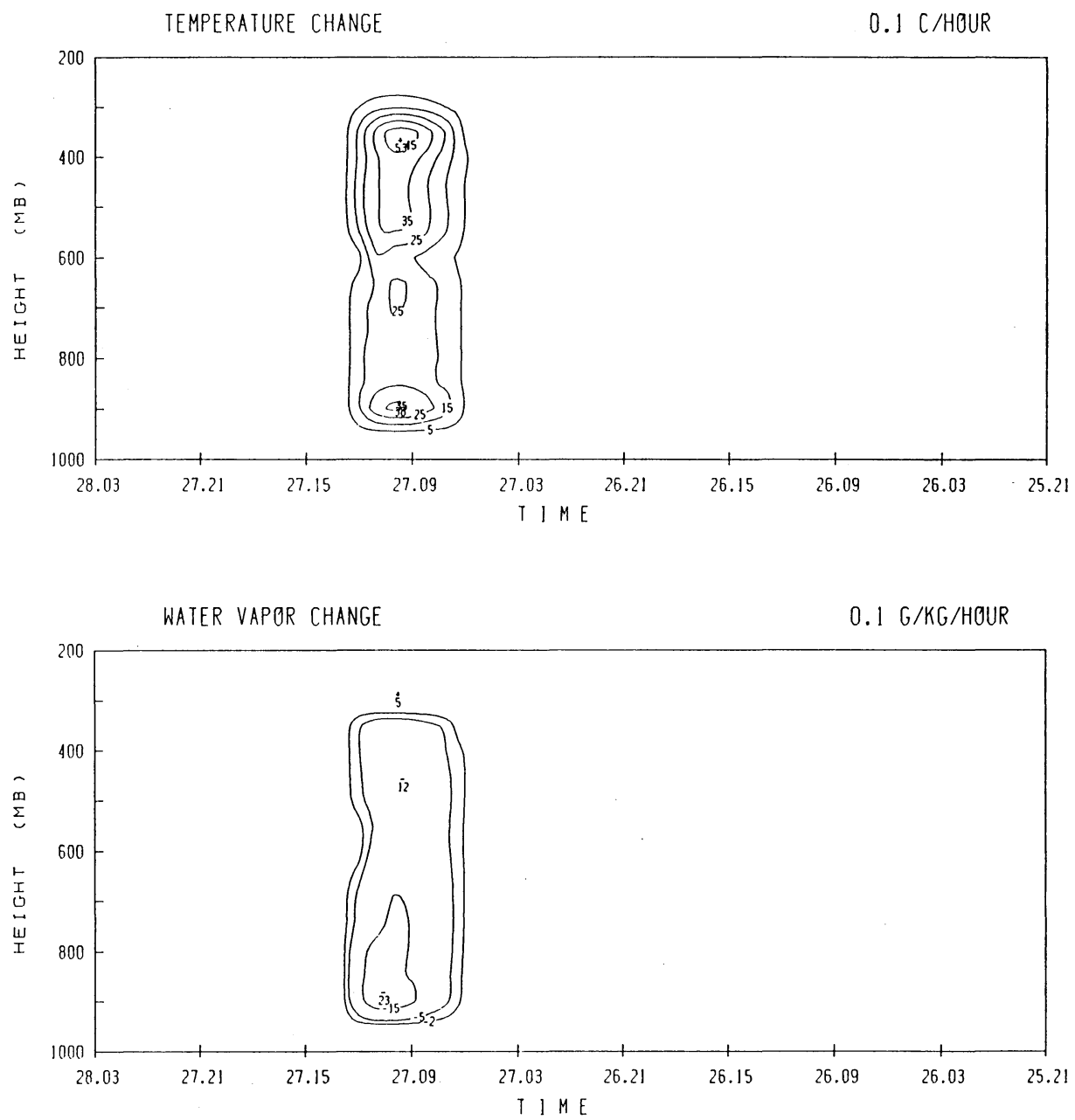

EQUiVALENT TEMPERATURE CHANGE

0.1 C HOUR

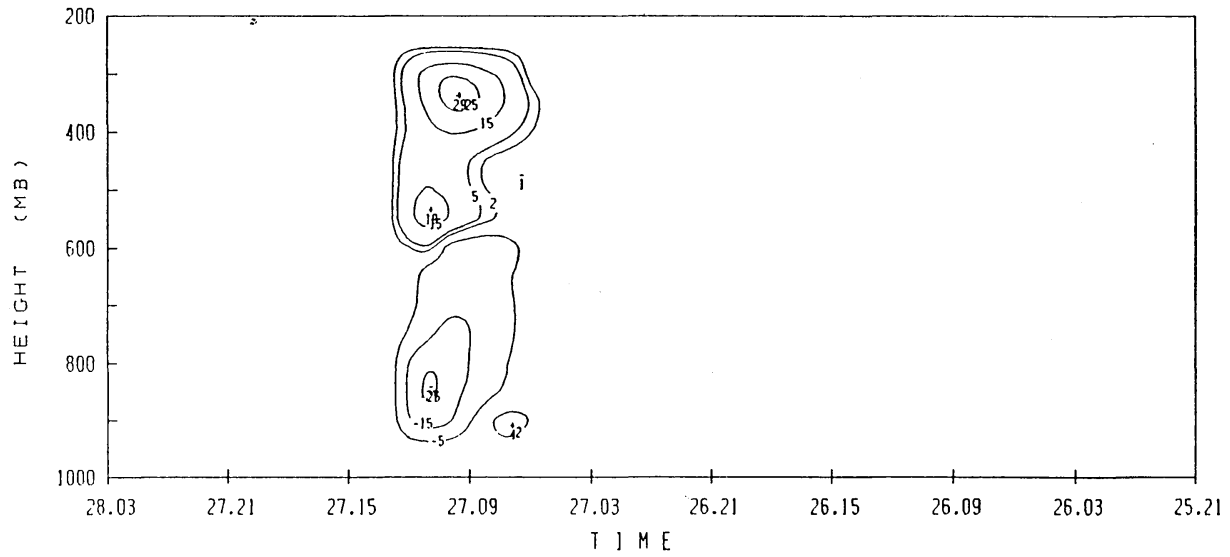

Fig. 11 Vertical time sections of changing rate of temperature, moisture and equivalent temperature $h / c_{p}$ caused by $C U$. Unit is $0.1 \mathrm{C} /$ hour, $0.1 \mathrm{~g} / \mathrm{kg} /$ hour and $0.1 \mathrm{C} / \mathrm{hour}$, respectively. 

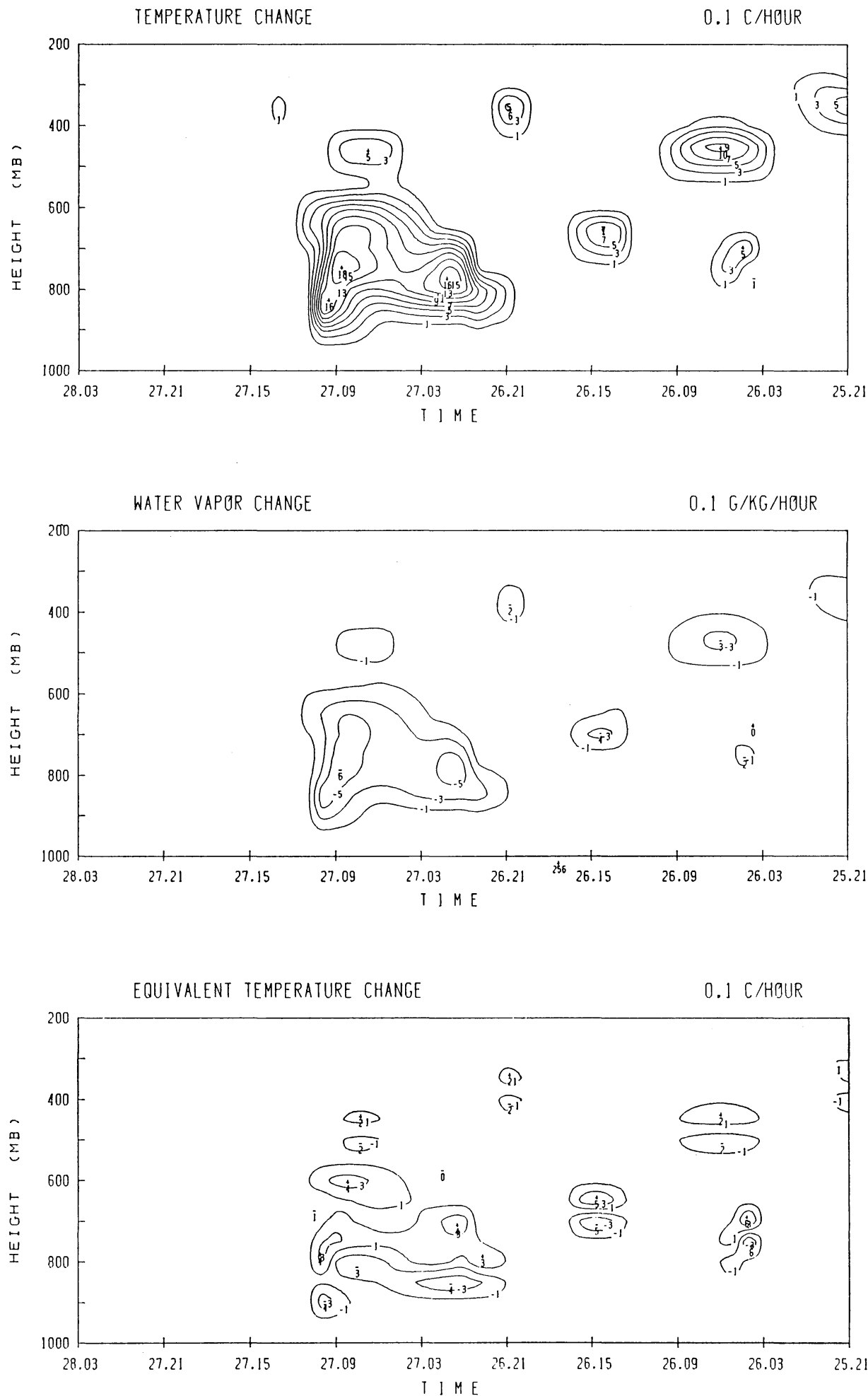

Fig. 12 As in Fig. 11 except for $M L$. Note that contour interval is different from that in Fig. 11. 
TEMPERATURE CHANGE

0.1 C HOUR

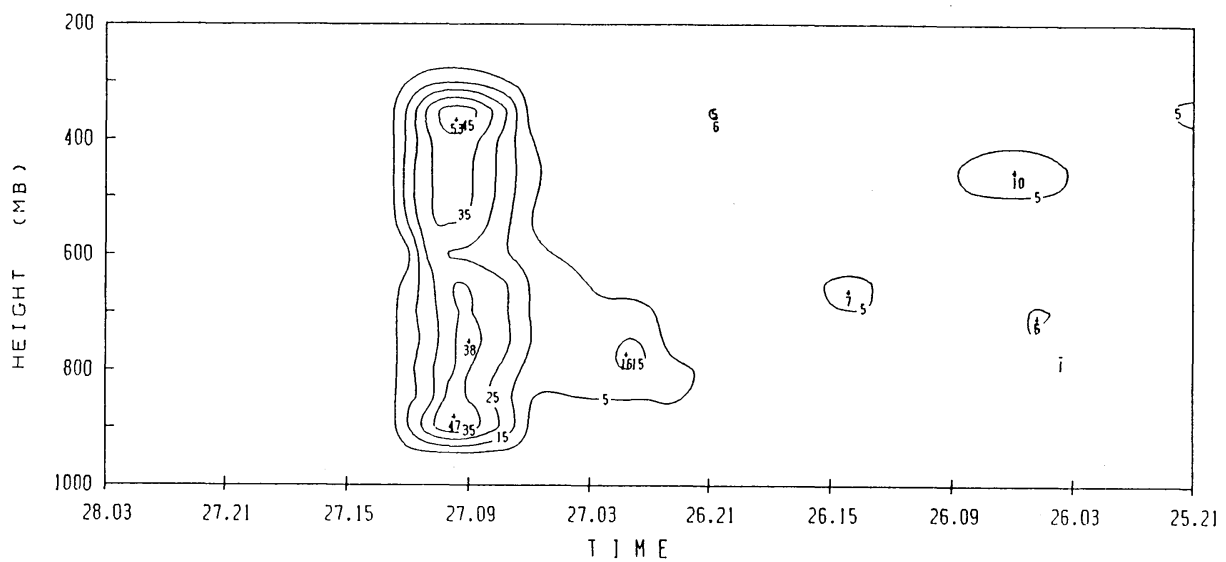

WATER VAPOR CHANGE

0.1 G/KG/HOUR

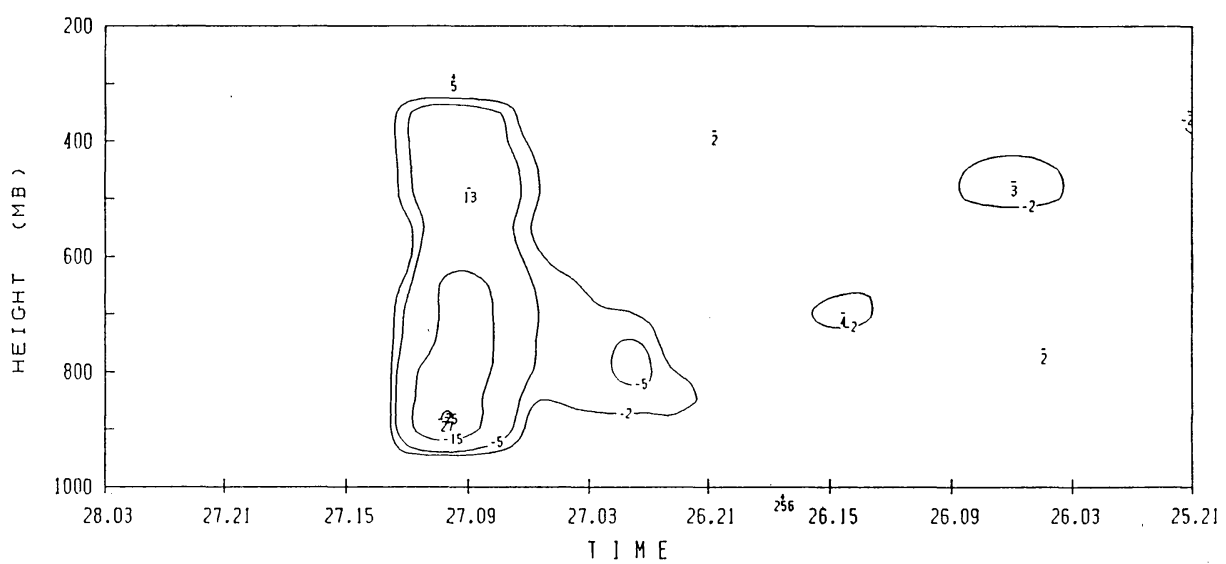

EQUIVALENT TEMPERATURE CHANGE

$0.1 \mathrm{C} /$ HOUR

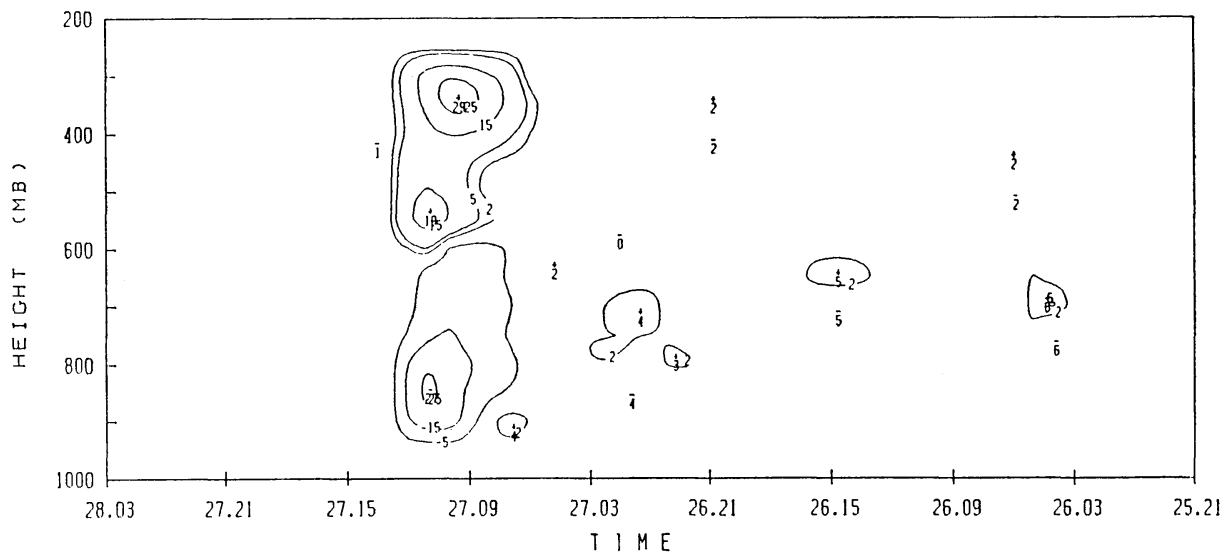

Fig. 13 As in Fig. 11 except for $C U+M L$. 
Warming was stronger in upper layer and on the hand, drying was stronger in lower layer, therefore, equivalent temperature increased in upper layer and decreased in lower layer. As a result, CU acted to stabilize the stratification. Since equivalent temperature is a conservative variable, the vertically integrated value of its time change is zero.

ML cloud has the similar effect to CU cloud, but the effect of it was weak and confined mainly in lower layer (Fig. 12). So, CU+ML effect is similar to $\mathrm{CU}$ effect (Fig. 13).

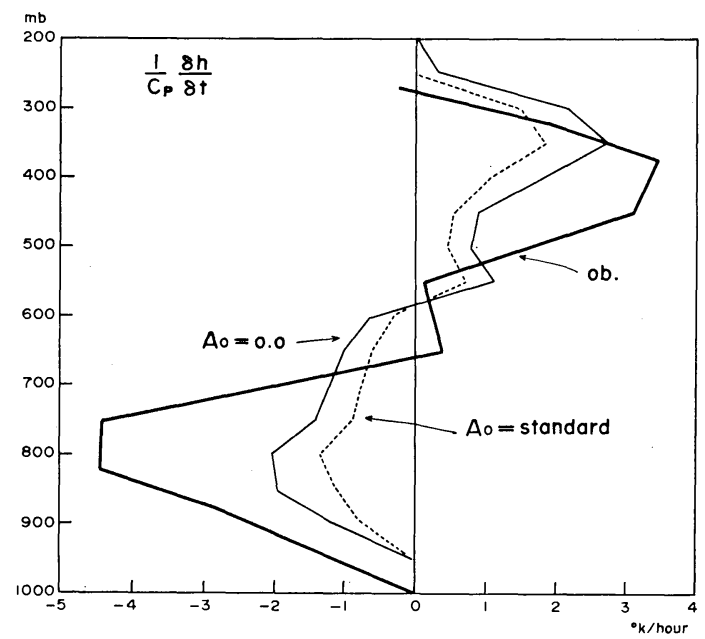

Fig. 14 Diabatic equivalent temperature changing rate. A thick solid line indicates changing rate during 03-09 LST 27 obtained by diagnostic study (NY). A dotted line indicates changnig rate obtained by model calculation during 06-12 LST 27.
Changing rates of equivalent temperature by $\mathrm{LSC}+\mathrm{ML}+\mathrm{CU}$ calculated during heavy rainfalls for the standard- $A_{0}$ and zero- $A_{0}$ cases are shown in Fig. 14. The changing rate of equivalent temperature evaluated by budget analysis (NY) is presented in Fig. 14 for comparison.

The general feature of the vertical distribution of the changing rate calculated in the model agrees well with that of the rate evaluated in the budget analysis. However the magnitude of the former is considerably smaller than that of the latter. The difference seems to be too large to be explained fully by the time-smoothing of the large-scale forcing terms. We speculate following causes of the discrepancy:

1) errors in the evaluation of large-scale forcing terms,

2) appling Lord-Arakawa's "baseline cloud function",

3) some incompleteness of the physical process in the model, though we do not get definite conclusions.

\section{Discussion}

In the Baiu frontal zone, cloud height distribution, mass flux, precipitation, thermodynamic variable's change in environment evaluated by the model seem to be adequate as far as comparing with the results of diagnostic studies. It is found, however, that the values obtained in the model are considerably smaller than these in the diagnostic study when the Lord-Arakawa's "baseline cloud work function" is used. In order to examine the effect of the "baseline cloud work function", we make other calculation with zero

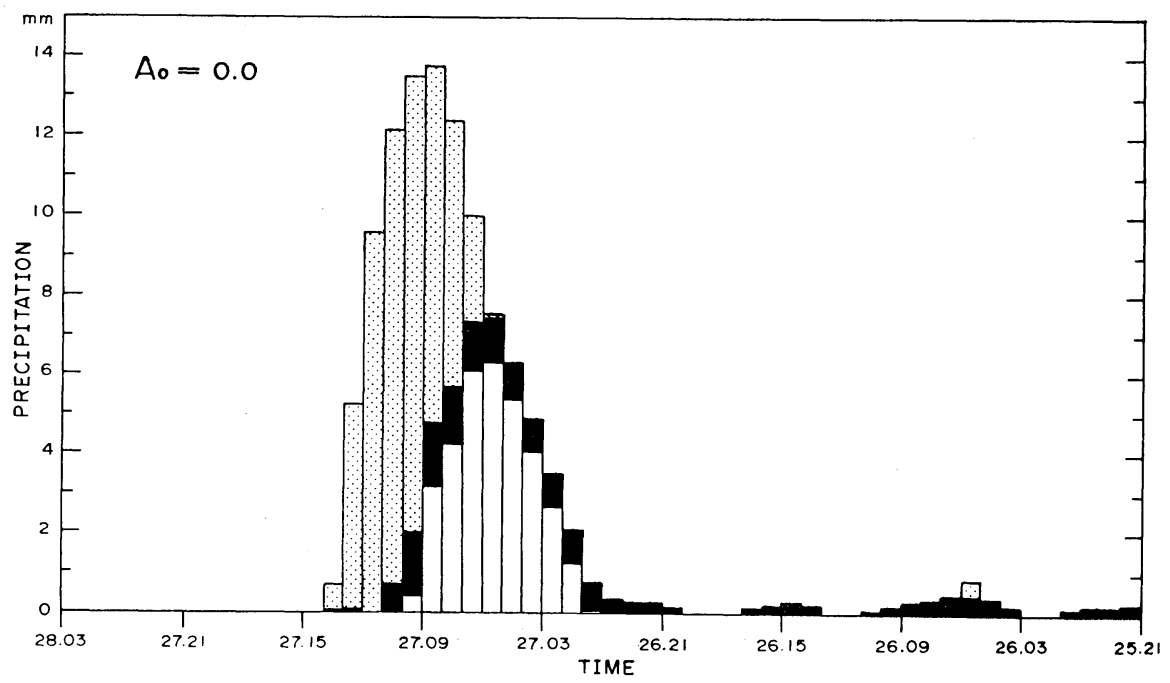

Fig. 15 As in Fig. 6A except for $A_{0}=0$. 
baseline cloud work function $\left(A_{0}=0\right)$. LordArakawa's "baseline cloud work function" works to suppress the high cumulus cloud. The use of "zero baseline cloud work function" in the model tends to produce the higher cloud. Fig. 15 shows the precipitation of this case. Peak precipitation rate was $\sim 14 \mathrm{~mm} /$ hour and total amount of rain was $107 \mathrm{~mm}$ (see Table 1). Equivalent temperature change is also shown in Fig. 14. Top of the highest cloud locates in $200 \mathrm{mb}$ layer $(\sim 12 \mathrm{~km})$. The results of $A_{0}=0$ case seem to be more similar to those of the diagnostic study.

We make following speculations for the difference between $A_{0}$ in the tropical regions and that in Baiu frontal heavy rainfall area. In the tropical regions, the middle and upper troposphere are usually dry and $h_{c}-h$ is large $\left(h_{c}: h\right.$ in cumulus). Therefore, the amount of evaporation at the lateral boundary of cumulus will be large and the cooling due to the evaporation will work to suppress the convection. In the heavy rainfall area, whole troposphere is moist and $h_{c}-h$ is small. The cooling due to the evaporation will be small. This will explain why $A_{0}$ is large in the tropical region while $A_{0}$ seems to be small in the heavy rainfall area.

The results of the present study suggest that $A_{0}(\lambda)$ is not necessarily universal function but depends on synoptic situation, season, place and other factors. Further study will be needed to ascertain this problem.

Another calculation without $\mathrm{CU}$ process also has made and results are shown in Table 1. In case of NO CU experiment, LSC rain increases but total amount of precipitation decreases as compared with that in the model including CU. It is concluded that contribution of $\mathrm{CU}$ to precipitation is great.

\section{Summary}

Real data response of A-S cumulus parameterization and other convective process are studied for the heavy rainfalls occurred over Kyushu on June 27, 1972.

We got the following conclusions from studies above:

(1) Model simulates accurately observed features (such as cloud height, mass flux, precipitation, time change of thermodynamic variables) to some extent.

(2) ML plays major role of the convective processes within the warm front before the onset of heavy rainfalls.

(3) LSC plays major role in the earlier half of the heavy rainfall period while deep CU plays major role during the latter half of the heavy rainfall period.

(4) CU+ML upward mass flux is approximately equal to the large-scale upward mass flux.

(5) During heavy rainfall period, $\mathrm{ML}+\mathrm{CU}$ works to stabilize the stratification cancelling the destabilizing effect of the large-scale forcing.

(6) The results of experiment with zero $A_{0}\left(A_{0}\right.$ : baseline cloud work function) agree more accurately with the result of diagnostic study as compared with the results of experiment with non zero $A_{0}$ (Lord and Arakawa (1980)). This suggests that $A_{0}$ is not necessarily universal function of cloud height, but depends on synoptic situation.

\section{Acknowledgements}

The authors express their heartly thanks to Miss T. Akiyama for reading the manuscript and giving helpful advices. Thanks are extended to Miss H. Imai for drafting the figures.

\section{Appendix A: Arakawa-Schubert CU model}

Arakawa and Schubert (1974) defined the "cloud work function" $A(\lambda)$. It is the rate of generation of kinetic energy of the clouds, which have fractional entrainment rates between $\lambda$ and $\lambda+d \lambda$ per unit mass flux, due to work done by buoyancy forces. (It is assumed that a single positive parameter $\lambda$ can fully characterize a cloud type.) A-S introduced quasi-equilibrium assumption i.e.

$$
\frac{d A(\lambda)}{d t}=\left[\frac{d A(\lambda)}{d t}\right]_{C}+\left[\frac{d A(\lambda)}{d t}\right]_{L S} \sim 0
$$

when type $\lambda$ clouds exist. In equation (A1) subscripts $\mathrm{C}$ and LS denote, the cloud terms and the large-scale terms respectively. The quasiequilibrium assumption means that the largescale destabilization effects and stabilization effects due to cloud terms are nearly cancelled out by each other when the clouds exist. The cloud terms express the changing rate of cloud work function by cloud-cloud interaction. Generally speaking, the cloud terms are negative and the redistribution of heat and moisture by clouds has the stabilizing effect of stratification. The cloud terms are written in the form

$$
\left[\frac{d A(\lambda)}{d t}\right]_{C}=\int^{\lambda_{\max }} K\left(\lambda, \lambda^{\prime}\right) M_{b}\left(\lambda^{\prime}\right) d \lambda^{\prime}
$$


at PBL (Planetary Boundary Layer) top.

The $K\left(\lambda, \lambda^{\prime}\right) M_{b}\left(\lambda^{\prime}\right) d \lambda^{\prime}$ is the rate of decrease (stabilization) of the cloud work function for type $\lambda$ clouds through the modification of the environment by type $\lambda^{\prime}$ clouds.

The large-scale terms in r.h.s. of equation (1) is the changing rate of the cloud work function for type $\lambda$ clouds through the modification of the environment by the large-scale processes, such as large-scale three dimensional advection, surface eddy fluxes and radiational heating terms.

To determine $M b(\lambda)$, we consider the three situations mentioned below;

(i) $A(\lambda) \leqq A_{0}(\lambda)$

Type clouds don't exist, i.e., $M b(\lambda)=0$ because of the insufficiency in buoyancy force.

(ii) $A(\lambda)>A_{0}(\lambda)$ and $d A(\lambda) / d t<0$

Even when $A(\lambda)$ is larger than $A_{0}(\lambda)$, type $\lambda$ clouds don't exist $(M b(\lambda)=0)$ if the net increase of $A(\lambda)$ by the large-scale term and cumulus term is negative.

(iii) $A(\lambda)>A_{0}(\lambda)$ and $d A(\lambda) / d t \geqq 0$

Type $\lambda$ clouds exist $(M b(\lambda)>0)$

$A_{0}(\lambda)$ is "baseline cloud work function" given as the function of cloud top height. The physical implication of $A_{0}$ is the vertical integrated buoyant force necessary to develop the cumulus cloud against the dissipation.

Thus the equations of determine mass flux at PBL top $M b(\lambda)$ are

$$
\left.\begin{array}{ll} 
& M_{b}(\lambda)=0 \\
& K\left(\lambda, \lambda^{\prime}\right) M_{b}\left(\lambda^{\prime}\right) d \lambda^{\prime}+\left[\frac{d A(\lambda)}{d t}\right]_{L S}=0 \\
& M_{b}(\lambda)=0 \\
K\left(\lambda, \lambda^{\prime}\right) M_{b}\left(\lambda^{\prime}\right) d \lambda^{\prime}+\left[\frac{d A(\lambda)}{d t}\right]_{L S}<0
\end{array}\right\}
$$

In GCM, $(d A(\lambda) / d t)_{L S}$ can be computed as $\left(A^{*}(\lambda)-A_{t-\Delta t}(\lambda)\right) / \Delta t$, where $A^{*}(\lambda)$ is $A(\lambda)$ at time step $t$ and $A_{t-\Delta t}(\lambda)$ is $A(\lambda)$ resulted from adjustments at time step $t$ - $\Delta t$. After the adjustments at $t-\Delta t, A(\lambda)_{t-\Delta t}$ is nearly equal to $A_{0}(\lambda)$, so we can get an approximate relation

$$
\left[\frac{d A(\lambda)}{d t}\right]_{L S}=\frac{A^{*}(\lambda)-A_{0}(\lambda)}{\Delta t}
$$

\section{Appendix B: Ice phase parameterization}

Yamazaki model includes approximately the effects of ice phase. When the environmental temperature $\bar{T}(z)$ is less than the critical tempera- ture $T_{c r}$ (here we assume it to be $-15^{\circ} \mathrm{C}$ ), we use $y$ defined below instead of $h$.

$$
y=h+L_{i} \cdot q=C_{p}+g \cdot z+L_{f} \cdot q
$$

where

$$
L_{f}=L+L_{i}
$$

where $L$ is the latent heat of vaporization per unit mass of water vapor, $L_{i}$ is the latent heat of fusion and $L_{f}$ is the latent heat of sublimation.

In the ice phase layer $\left(\bar{T}(z) \leqq-15^{\circ} \mathrm{C}\right), y$ is approximately conserved, while in the liquid phase layer $\left(\bar{T}(z)>-15^{\circ} \mathrm{C}\right), h$ is approximately conserved. We assume that phase change occures adruptly at the level of $T_{c r}$. Because of the difference between saturation water vapor pressure on ice and water, excess water vapor sublimates. At the same time, cloud liquid water freeze and release the latent heat. The temperature change due to those process at $T_{c r}$ level is

$$
\Delta T=\left(L_{f} \cdot \Delta q+L_{i} \cdot l\right) / c_{p}
$$

where $l$ is liquid water content, $\Delta q$ is difference between the saturated mixing ratio on ice and on water.

These additional heating in the cloud due to phase change generates buoyancy force and makes cloud work function larger. This means that cloud top is raised when the ice phase is included in CUP. We assume that precipitation from ice phase layer is in ice phase (i.e. snowfall), and snowfall melts at $0^{\circ} \mathrm{C}$ level to cool the environment.

\section{References}

Akiyama, T., 1973: The large-scale aspects of the characteristic features of the Baiu front. Pap. Met. Geoph., 24, 157-188.

, 1974: Mesoscale organization of cumulus convection in the large-scale rainband in Baiu season. J. Met. Soc. Japan, 52, 448-451.

, 1978: Mesoscale pulsation of convective rain in medium-scale disturbances developed in Baiu front. J. Met. Soc. Japan, 56, 267-283.

1979: Variation of thermal stratification in subtropical medium-scale disturbances. J. Met. Soc. Japan, 57, 587-598.

Arakawa, A. and Y. Mintz, 1974: The UCLA Atmospheric General Circulation Model. Notes distributed at the workshop, 25 March-4 April, 1974. Dept. Met., UCLA.

and W. H. Schubert, 1974: Interaction of a cumulus cloud ensemble with the large-scale environment, Part I. J. Atmos. Sci., 31, 674-701.

Cho, H.-R., and Y. Ogura, 1974: A relationship between cloud activity and low-level convergence as observed in Reed-Recker's composite easterly 
waves. J. Atmos. Sci., 31, 2058-2065.

Johnson, R. H., 1976: The role of convective-scale precipitation downdrafts in cumulus and synopticscale interactions. J. Atmos. Sci., 33, 1890-1910. 1978: Cumulus transports in a tropical wave composite for Phase III of GATE. J. Atmos. Sci., 35, 484-494.

Lewis, J. M., 1975: Test of the Ogura-Cho model on a prefrontal squall line case. Mon. Wea. Rev., 103, 764-778.

Lord, S. J., and A. Arakawa, 1980: Interaction of cumulus cloud ensemble with the large-scale environment. Part II. J. Atmos. Sci., 37, $2677-$ 2692.

Matsumoto, S. and T. Akiyama, 1970: Mesoscale disturbances and related rainfall cells embedded in Baiu front, with a proposal on the role of convective momentum transfer. J. Met. Soc. Japan, 48, 91-102.

McGregor, J. L., L. M. Leslie, and D. J. Gauntlett, 1978, The ANMRC limited-area model. Mon. Wea. Rev., 106, 427-438.

Ninomiya, K., 1978: Heavy rainfalls associated with frontal depression in Asian subtropical humid region (I). J. Met. Soc. Japan, 56, 253-266.

, and K. Yamazaki, 1979: Heavy rainfalls associated with frontal depression in Asian subtropical humid region (II). J. Met. Soc. Japan, 57, 399-413.

-, and T. Akiyama, 1972: Medium-scale echo clusters in the Baiu front as revealed by multi-radar composite echo maps. J. Met. Soc. Japan, 50, 558-569.

Nitta, T., 1975: Observational determination of cloud mass flux distributions. J. Atmo.s Sci., 32, 73-91.

- 1977: Response of cumulus updraft and downdraft to GATE A/B-scale motion systems. J. Atmos. Sci., 34, 1163-1186.

- 1978: A diagnostic study of interaction of cumulus updrafts and downdrafts with largescale motions in GATE. J. Met. Soc. Japan, 56, 232-241.

Ogura, Y. and H.-R. Cho, 1973: Diagnostic determination of cumulus cloud population from observed large-scale variables. J. Atmos. Sci., 30, 1276-1286.

Tokioka, T., K. Yamazaki, I. Yagai, 1980: On the atmospheric genaral circulation model of Meteorological Research Institute. Gross Wetter, 18, 1-39 (in Japanese).

Wada, M., 1977: The properties of typhoon-scale disturbances produced by Arakawa-Schubert parameterization. J. Met. Soc. Japan, 55, 364-391.

Yanai, M., S. Esbensen and J.-H. Chu, 1973: Determination of bulk properties of tropical cloud clusters from large-scale heat and moisture budgets. J. Atmos. Sci., 30, 611-627.

, J.-H. Chu, T. E. Stark and T. Nitta, 1976: Response of deep and shallow tropical maritime cumuli to large-scale processes. J. Atmos. Sci., 33, 976-991.

\section{豪雨時のリアル・データに対する Arakawa-Schubert 積雲 パラメタリゼーション・モテルの応答}

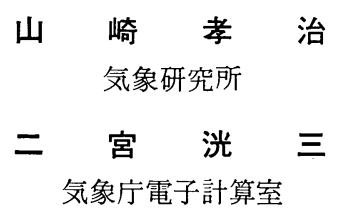

Arakawa-Schubert の積雲パラメタリゼーション (CU) を，1972年6月27日に九州で発生した豪雨の場合に 適用して，その応答を調べる。

観測された大規模場の 3 次元的移流による温度-水蒸気量の变化を与えて, 簡単な 1 次元モデル (CU, 大規模 場の凝結(LSC), 中層対流調節 (ML) を含む) を積分して, 大規模場の影響を調べる。モデルは, 雲の高さ, 降 水量などの観測された特徵をよく再現する。モデルの計算結果によると, 低気圧の暖域中では, ML が重要な役割 を果たし，LSC とCU は豪雨の起きた前線のすとの部分 (training portion) で重要な働きをしている。豪雨の 前半では，LSC が重要な働きをし，後半では CU が重要な働きをする。

大規模な移流による成層の不安定化に抗して CU と ML は成層を安定化するように働く。豪雨時のマス・ フラックスはほぼ大規模場の上昇流に等しい。基準雲仕事関数 (baseline cloud work function) $A_{0}$ をLordArakawa (1980) の值ではなくゼロにした方が観測との一致はよい。 